\title{
ASSESSMENT OF EFFICACY OF ELECTRONIC VACUUM ASPIRATION WITH INTRAVENOUS ANALGESIA
}

\author{
Afeera Afsheen, Aisha Shahid, Bushra Iftikhar, Rabiah Anwar, Javaria Nosheen*, Amera Tariq \\ Pakistan Naval Ship Shifa Hospital, Karachi Pakistan, *Combined Military Hospital Abbottabad/National University of Medical Sciences (NUMS) Pakistan
}

\begin{abstract}
Objective: To assess efficacy of elecrtonic vacuum aspiration in evacuation of retained product of conception with intravenous analgesia.

Study Design: A prospective observational study.

Place and Duration of Study: Department of Gynaecology and Obstetrics, Pakistan Naval Ship Shifa Hospital, Karachi Pakistan, from Jan to Jun 2018.

Methodology: All patients who were intended to undergo Electronic Vacuum Aspiration due to retained products of conception, early fetal demise, septic induced abortions and molar (all upto 12 weeks of gestation) were enrolled in this study after obtaining informed consent. Outcome measures of study were efficacy (defined as completeness of the evacuation procedure confirmed by ultrasound), occurrence of complications like uterine perforation, excessive bleeding $>200 \mathrm{ml}$ and sepsis (diagnosed clinically or biochemically).

Results: A total of 1080 patients underwent electronic vacuum aspiration during the study period. Complete evacuation was achieved in $1026(95 \%)$ cases. Four $(<1 \%)$ patients experienced post procedure infection while none had uterine perforation. Average blood loss was $<100 \mathrm{ml}$ while $18(1.6 \%)$ patients had blood loss of $>200 \mathrm{ml}$.

Conclusion: Electronic vacuum aspiration is a safe and efficacious method of uterine evacuation. It does not require special equipment. It is easy to learn and is readily available as well as cost effective. Hence it's a very lucrative alternative to manual vacuum aspiration using I pass or medical termination of pregnancy in resource poor settings.
\end{abstract}

Keywords: Conception, Safety, Uterine evacuation, Vacuum aspiration.

This is an Open Access article distributed under the terms of the Creative Commons Attribution License (https://creativecommons.org/licenses/by-nc/4.0/), which permits unrestricted use, distribution, and reproduction in any medium, provided the original work is properly cited.

\section{INTRODUCTION}

Miscarriage is the commonest complication affecting $10-20 \%$ of clinically recognisable conceptions ${ }^{1}$. National health trust of UK reports that $15 \%$ of all pregnancies culminate in spontaneous miscarriage. These figures may differ in different health care facilities across the gloge ${ }^{2}$. It is estimated that two hundred and eleven million pregnancies around the world occur annually out of which about 46 million are eventually terminated by induced abortion ${ }^{2}$. Globally, majority of women are likely to experience at least one abortion by the age of $45^{3}$. Most of these terminations are carried out in the first trimester of pregnancy. It is roughly estimated that one-third of all abortions are performed under unsafe medical conditions, which unfortunately contributes to $13 \%$ of all maternal deaths ${ }^{3}$.

The scenario is not much different in our country. In Pakistan, estimated annual miscarriage rate is 29/ 1000 women aged 15-49 years. In public health sector, 197 thousand women receive treatment annually for post abortion complications 4 .

Thus the search for safer, more cost effective and

Correspondence: Dr Afeera Afsheen, Department of Obstetrics and Gynaecological, PNS Shifa Hospital, Karachi Pakistan

Received: 06 Jun 2020; revised received: 23 Nov 2020; accepted: 27 Nov 2020 easily available abortion method continues regionally as well as globally due to the great burden of disease and its ensuing complications. The main procedures for affecting abortion encompass vacuum aspiration, sharp curettage and medically induced abortion using misoprostol ${ }^{5}$. Vacuum aspiration, which is most commonly adopted method of first trimester terminations is safer and far less painful than sharp curettage and has been found to be more effective and less painful compared with medical abortions using mesoprostol ${ }^{5}$. Trials from around the globe have delineated high efficacy of vacuum aspiration in terms of accomplishing complete uterine evacuation rates between $95-100 \%{ }^{5}$. Vacuum aspiration entails the evacuation of products of conception by using a plastic or metal cannula, attached to a vacuum source. Electric vacuum aspiration (EVA) makes use of an electric vacuum pump whereas in manual vacuum aspiration (MVA), the vacuum is created using a hand-held, activated, plastic syringe. MVA has been in vogue for $>30$ years. Various researchers have documented diverse opinions on its safety. The preference of aspiration method whether electronic or vacuum is multifactorial based on availability, comfort and expertise of performing obstetrician and gynaecologist with one method and women acceptability and affordability ${ }^{6,7}$. Suction evacuation by using 
suction machine (electrically operated) is the method of choice in gestational trophoblastic disease carried out in settings of operation theatre under general anaesthesia due to risk of excessive haemorrhage. Expectant management and medical treatment with misoprostol in selected cases has many benefits including economy and avoidance of intervention related complications but when employed in patients with large volume of retained products have been found to be associated with an increase in complications, primarily infection and prolonged bleeding ${ }^{8}$. Many women continue to express a preference for surgical treatment, citing fears regarding pain, bleeding and length of time to resolution in non-surgical group and the need for repeated hospital visits ${ }^{8-10}$. Pakistan is a third world country where practising gynaecologists need to explore methods for affecting abortions which are safe, efficacious, easily available, acceptable and cost effective as well. Since one MVA I PASS device is expensive and not freely available everywhere especially in rural areas and has to be discarded after a specific number of procedures, there is need for an easily available, acceptable and cost effective method of abortion which is safe and efficacious. The technique of MVA has to be learnt. It is a bit more arduous and complicated compared to EVA.

Thus this study was undertaken at PNS Shifa to establish the safety and efficacy of EVA. Electronic vacuum aspiration was performed after soliciting informed consent of patient using Nelton catheter of size 16-24 according to dilatation of cervical os. It was attached to electronic suction machines to create vacuum. Intravenous tramol 50mg in dilution was given for pain relief. Confirmation of complete evacuation was done by trans vaginal scan performed 2-3 hours after the procedure. Nelton catheter is cheap and readily available and is discarded after the procedure. The technique can be easily learnt and even the midwives and lady health workers can confidently perform it in low risk patients without previous uterine scars in remote areas and resource poor settings.

\section{METHODOLOGY}

A prospective observational study was conducted in Gynaecology and Obstetrics department of Pakistan Naval Ship Shifa Hospital Karachi, from January to June 2018. Prior approval was taken from hospital ethical review board. All patients with gestational age of $<12$ weeks admitted or detained in gynaecological ward with the diagnosis of early fetal demise, anembryonic pregnancy incomplete miscarriage, missed mis- carriage, molar pregnancy, retained products of conception after child birth and septic induced abortion were included in the study after taking informed consent. Diagnosis was established using history, physical examination and ultrasonographic (US) scanning. Serum $\beta$ HCG were done when ultrasound was suggestive of retained products of conception while the history and examination were inconclusive of pregnancy and in cases of molar pregnancy. Patients with uterine anomalies, abnormal coagulation profile, bleeding disorders, known or expected ectopic pregnancy and haemodynamic instability were excluded from the study. For the purpose of study foetal demise was defined as lack of cardiac activity at crown-rump length (CRL) of $>6 \mathrm{~mm}$, anembryonic pregnancy included gestational sac with mean diameter of $>25 \mathrm{~mm}$ without an embryo, An incomplete miscarriage was defined as passage of products of conception with the residual anterior-posterior endometrial lining of $>15 \mathrm{~mm}$ and uterine size $<12$ weeks. After taking informed consent patients went under electronic vacuum aspiration (EVA) with Intravenous analgesia with injection tramol 50mg in dilution in labour room using 16-24 size nelton catheter attached to suction machine. Twenty five patients were given paracervical block with $10-20 \mathrm{ml}$ of $1 \%$ lignocaine who complained of pain despite single dose of diluted injection tramol intravenous administration.

Completeness of procedure was assessed through ultrasound performed to measure size of any remaining products of conception. It was labelled as incomplete when the anteroposterior diameter of Products of conception seen on ultrasound exceeded $15 \mathrm{~mm}$. Products of conception were sent for histopathology for confirmation of intrauterine pregnancy. Patients were kept in recovery room for $30 \mathrm{~min}$ and later transferred to their respective wards. The primary outcome measures assessed were the success rate of the procedure, defined as complete uterine evacuation (confirmed through transvaginal ultrasonography) and procedure related complications including uterine perforation, bleeding and infection. Blood loss was estimated by the operating physician, and in most cases was usually $<100 \mathrm{ml}$. Patients were asked for routine follow up at 1 week later or earlier if bleeding, foul smelling discharge or persistent lower abdominal pain or fever occurred.

Data was analyzed through SPSS-21. Quantitative variables like indications of electronic vacuum aspiration, efficacy or complete evacuation and complications like infection, blood loss $>200 \mathrm{ml}$ and uterine per- 
foration were expressed as frequencies and percentages. Mean and standard deviation were calculated for patient characteristics like age, parity and gestational age in weeks and days.

\section{RESULTS}

A total of 1080 patients underwent electronic vacuum aspiration. Complete evacuation was achieved in $1026(95 \%)$ of the cases. Four patients $(<1 \%)$ experienced post procedure infection while none had uterine perforation. Average blood loss was $<100 \mathrm{ml}$ in majority of patients while $18(1.6 \%)$ had blood loss of $>200$ $\mathrm{ml}$. The mean patient age in study population was 30.1 \pm 5 years, mean parity was $3 \pm 1.4$ children and mean gestational age was 9 weeks \pm 4 days. The commonest indication of EVA was anembryonic pregnancy in 253 $(23.4 \%)$ while least common indication was evacuation of retained products of conception after normal vaginal birth in $23(2.3 \%)$.

Table-I: Patient characteristics.

\begin{tabular}{l|c}
\hline Patients Characteristics & \\
\hline Marital Status & All married \\
\hline Age $($ Mean \pm SD) & $30.1 \pm 5$ years \\
\hline Parity (Mean \pm SD) & $3 \pm 1.4$ children \\
\hline Gestational age (Mean \pm SD) & 9 weeks \pm 5 days \\
\hline
\end{tabular}

\begin{tabular}{|c|c|}
\hline \multicolumn{2}{|c|}{$\begin{array}{l}\text { Table-II: Indications of electronic vacuum } \\
\text { aspiration }(n=1080) \text {. }\end{array}$} \\
\hline $\begin{array}{l}\text { Indications of Electronic } \\
\text { Vacuum Aspiration }\end{array}$ & n (\%) \\
\hline Anembryonic pregnancy & $253(23.4)$ \\
\hline Early fetal demise & $405(37.5)$ \\
\hline Incomplete miscarriage & $207(19.16)$ \\
\hline $\begin{array}{l}\text { Retained products of conception } \\
\text { after Normal Vaginal Delivery }\end{array}$ & $25(2.3)$ \\
\hline Partial mole & $100(9.6)$ \\
\hline
\end{tabular}

Table-III: Efficacy and complications of electronic vacuum aspiration $(n=1080)$.

\begin{tabular}{l|c}
\hline Efficacy \& Complications & n (\%) \\
\hline Success & $1026(95)$ \\
\hline Incomplete evacuation & $54(5)$ \\
\hline Infection & $4(<0.5)$ \\
\hline Excessive blood loss & $18(1.6)$ \\
\hline Uterine perforation & - \\
\hline
\end{tabular}

\section{DISCUSSION}

Miscarriages constitute major burden of early pregnancy disorders globally as well as in our country. A study carried out by the Population Council of Pakistan in 2012 estimated the number of women who reported to both private or public healthcare facilities for abortion to be 696000 , with 267000 admitted to public sector facilities and 429000 to private institutions ${ }^{11}$. In our country conventionally the most commonly adopted method of uterine evacuation has been dilation and curettage (D \& C) also known as dilation and evacuation (D \& E) in which gradual dilation of the cervix with Hegars dilators is done followed by and uterine evacuation with sponge-holding forceps or ovum forceps, and at the end, the uterine cavity is explored with a sharp or a blunt curette to ensure that it is empty ${ }^{11}$. This is performed under General anaesthesia in the settings of an operation theatre. Thus it requires the expertise of an anaesthetist as well as a gynaecologist and is associated with more complications of both surgery and anaesthesia. The off-label use of misoprostol for the induction of labour and uterine evacuation began in some hospitals in this country about 15 years ago when varried reports of its efficacy and safety started appearing in the literature ${ }^{11}$. After it was put on the WHO Essential Drug List, its use was approved for inducing abortions in 201911. Both FIGO and WHO recommend a shift from sharp curettage to the use of aspiration techniques due to avoidance of anaesthesia related complications, cost effectiveness, easy learning curve and accessibility and availability of these methods compared to conventional dilatation and curettage under general anaesthesia which requires more expertise and are costlier ${ }^{11}$. While Manual Vacuum Aspiration needs special equipment and expertise and is costlier as compared to EVA done using nelton catheter with intravenous analgesia.

In our study complete evacuation was achieved in $1026(95 \%)$ cases which is consistent with figures reported by Sultana et al who quoted complete evacuation (success rate) to be $89 \%$ for MVA and $91.4 \%$ for EVA $^{12}$,. Whereas Mansoor et al, conducted a comparative study between MVA and Dilatation and curettage under general anaesthesia and found the efficacy to be $96 \%$ and $100 \%$ respectively ${ }^{4}$. Russo et al, conducted a multicentric retrospective chart review study at Columbia to compare medical termination with aspiration technique in pregnancy of $<49$ days in 2014-15 and documented lesser adverse effects in the aspiration group 5.8 vs $2.7 \%$ respectively ${ }^{13}$.

Alisa et al, recorded no difference in rates of uterine reaspiration while comparing outcomes of manual $(2.2 \%)$ with electronic $(1.7 \%)$ vacuum aspiration in USA. They came across 25 procedure related complications like uterine perforation, haemorrhage necessitating blood transfusion in manual compared to 15 in 
electronic group ${ }^{14}$, while in our study incomplete evacuation was seen in 5\% and blood loss in excess of 200 $\mathrm{ml}$ in $1.6 \%$ of cases whereas infection in $<1 \%$.

Padron et al conducted a comparative trial of MVA and EVA in USA and observed longer average procedural time with electrical vacuum aspiration (8.1 $\mathrm{min})$ than manual vacuum aspiration $(7.6 \mathrm{~min})^{15}$. We did not include procedure time as our study variable. They observed excessive amount of blood loss with increasing gestational age and more blood loss with electrical vacuum aspiration $(21.6 \mathrm{ml})$ than manual vacuum aspiration $(16.6 \mathrm{ml})$. There were no complications during procedure with both vacuum sources. Incomplete evacuation rate with MVA was $4 \%$ and with electrical vacuum aspiration $15(2 \%)$ while we found it to be $5 \%$ in our study.

Lui and Chang compared surgical abortions and medical abortions in first trimester miscarriages. Complete abortion rates were 97 and 95\% respectively in Hong Kong. Risk of significant bleeding is $<5 \%$ in vacuum aspiration while major complications were $<1 \%{ }^{16}$. Khan et al, conducted a systematic review and network meta analysis of 46 trials from Cochrane library to assess the effectiveness and safety of treatment options for first trimester miscarriages including expectant management, sharp dilatation and curettage, EVA, MVA and misoprostol. Results showed low effectiveness of expectant method and similar effectiveness of medical and surgical modalities. Analgesia needs were less in EVA group while more complications were observed in $\mathrm{MVA}^{17}$.

A retrospective analysis of California fee for service medicaid claims data, delineated serious complication rates were $<1 \%$ in aspiration techniques of miscarriages which is lower than the percentage of around $5 \%$ quoted by us ${ }^{18}$.

Reaspiration rates $<0.1-8 \%$ have been reported by White et al, related to gestational age, provider experience and use of ultrasound guidance. Most patients had a blood loss of $<100 \mathrm{ml}$ again coinciding with Mean blood loss of $75.7 \pm 35.5 \mathrm{ml}$ in EVA group in study quoted earlier. Likewise there was no case of major haemorrhage requiring blood transfusion. Procedure related uterine perforation which occurred in $2(2.4 \%)$ patients both belonging to EVA group in their study was not encountered in our patients ${ }^{19}$. The mean hospital stay, pain scores and cost of treatment and operating time were not analysed in our study. Electronic Vacuum Aspiration was performed with intravenous analgesia in contrast to total intravenous anaesthesia as safety of analgesia over anesthesia cannot be over emphasized.

\section{CONCLUSION}

EVA using nelton catheter with systemic analgesia is a safe and cost effective alternative to traditional Evacuation of Retained Products of Conception under general anaesthesia. It is superior to Manual Vacuum Aspiration in terms of cost, less need for training and expertise development as it is simpler and easier to perform. It ensures almost complete evacuation and does not need strict follow up as medical termination with misoprostol.

\section{CONFLICT OF INTEREST}

This study has no conflict of interest to be declared by any author.

\section{REFERENCES}

1. Saeed S, Manzoor B, Akram S. Comparison of Efficacy of Manual Vacuum Aspiration versus D\&C in Patients with Incomplete and Missed Miscarriage. Pak J Med Health Sci 2019; 13(3): 582-85.

2. Ara J, Iftekhar T, Ijaz S, Qazi NH, Sultana N. Comparison of manual vacuum aspiration versus conventional evacuation of retained products. Ann Pak Ins Med Sci 2018; 14(1): 90-92.

3. Ahsan A, Jafarey SN. Unsafe abortion: Global picture and situation in Pakistan. J Pak Med Assoc 2008; 58(1): 660-1.

4. Mansoor A, Jabeen J, Mansoor MH. Assessment of efficacy and safety of manual vacuum aspiration. JRMC 2013; 17(1): 46-49.

5. Bano K, Iqbal S. Alternative to surgical evacuation of uterus: Misoprostol for post abortion care. J Surg Pak 2009; 14(1): 53-57.

6. Say L, Kulier R, Gulmezoglu M, Campana A. Medical versus surgical methods for first trimester termination of pregnancy. Cochrane Data base Syst Rev 2005; 1(1): CD003037.

7. Shelley JM, Healy D, Grover S. A randomized trial of surgical, medical and expectant management of first trimester spontaneous miscarriage. Aust NZJ Obstet Gynecol 2005; 45(1): 122-7.

8. Roblin P. Vacuum aspiration. In: Rowlands S,editor. Abortion care, Cambridge, UK: Cambridge University Press; 2014.pp71-75.

9. Allen $\mathrm{RH}$, Goldberg AB. Cervical dilatation before first trimester surgical abortion(14 weeks gestation). Contracept 2016; 93(4): 277-91.

10. Ireland LD, Gatter M, Chen AY. Medical compared with surgical abortion for effective pregnancy termination in first trimester. Obstet Gynaecol 2015; 126(1): 22-28.

11. Zaidi S, Yasmin H, Hassan L, Khakwani, Sami S, Abbas T. Replacement of dilation and curettage/evacuation by manual vacuum aspiration and medical abortion, and the introduction of postabortion contraception in Pakistan. Inter J Gynecol Obstet 2014; 126(4): 40-44.

12. Tasnim N, Mahmud G, Fatima S, Sultana N. Manual vacuum aspiration: a safe and cost-effective substitute of Electric vacuum aspiration for the surgical management of early pregnancy loss. J Pak Med Assoc 2011; 61(1): 149-53.

13. Baldwin MK, Bednerak PH, Russo J. Safety and effectiveness of medication and aspiration abortion before or during the sixth week of pregnancy:A retrospective multicentre study.Contracep 2020; 102(1): 13-17.

14. Goldberg A, Dean G, Kang M, Yousaf S, Darney P. Manual versus electric vacuum aspiration for early first-trimester abor- 
tion: a controlled study of complication rates. Obstet Gynecol 2004; 103(2): 101-7.

15. Padrón L, Rezende J, Filho J, Amim J, Yazaki SS, Rafael CC, et al. Manual compared with electricvacuum aspiration for treatment of molar pregnancy. Obstet Gynecol 2018; 131(1): 652-4.

16. Lui MW, Ho PC. First trimester termination of pregnancy. Best Pract Res Clin Obstet Gynaecol 2019; 63(1): 13-23.

17. Al-Watter BH, Murugesu N, Tobias A, Zamora J, Khan KS. Management of first trimester miscarriage:a systematic review and network metaanalysis. Human Reproduct Update 2019; 25(3): 362-74.

18. Upadhyay UD, Desai S, Zlidar V, Weitz TA, Grossman D, Anderson $\mathrm{P}$, et al. Incidence of emergency department visits and complications after abortion. Obstet Gynaecol 2015; 125(1): 175-3.

19. Grossman D, White K, Harris L, Reeves M, Blumenthal PD, Winikoff $\mathrm{B}$, et al. Continuing pregnancy after mifepristone and reversal of first trimester medical abortion:a systematic review. Contracept 2015; 92(3): 206-11. 